\title{
NOVOS MEIOS DE COOPERAÇÃO CIENTÍFICA PARA A INOVAÇÃO DA GOVERNANÇA AMBIENTAL DA MACROMETRÓPOLE PAULISTA ${ }^{1}$
}

\author{
Pedro Henrique Campello TORRES ${ }^{2}$ \\ Pedro Roberto JACOBI ${ }^{3}$
}

Não haverá verdadeira resposta à crise ecológica a não ser em escala planetária e com a condição de que se opere uma autêntica revolução política, social e cultural reorientando os objetivos da produção de bens materiais e imateriais. Essa revolução deverá concernir, portanto, não só às relaçóes de forças visíveis em grande escala, mas também aos domínios moleculares de sensibilidade, inteligência e desejo. (GUATTARI, 2011, p.9).

\footnotetext{
Agradecemos enormemente à colaboração e parceria dos professores Leandra Gonçalves (IMAR/UNIFESP), Leandro Giatti (FSP/USP), Klaus Frey (UFABC) e Sandra Momm (UFABC), em todo processo de construção coletiva que tem, como produto final, o presente dossiê especial. Sem eles o processo não teria existido.

2 Doutor em Ciências Sociais (PUC-Rio). Professor Colaborador de Gestão Ambiental na Escola de Artes, Ciências e Humanidades, Universidade de São Paulo (USP), São Paulo - SP - Brasil. ORCID: https://orcid.org/0000-00020468-4329. phcampellotorres@gmail.com.

3 Doutor em Sociologia (USP), Professor Titular Sênior no Programa de Pós-Graduação em Ciência Ambiental, Instituto de Energia e Ambiente, Universidade de São Paulo (USP), São Paulo - SP - Brasil.. ORCID: https://orcid. org/0000-0001-6143-3019.prjacobi@gmail.com.
} 
Foto 1 - Ruralidades Metropolitanas e a Emergência Climática

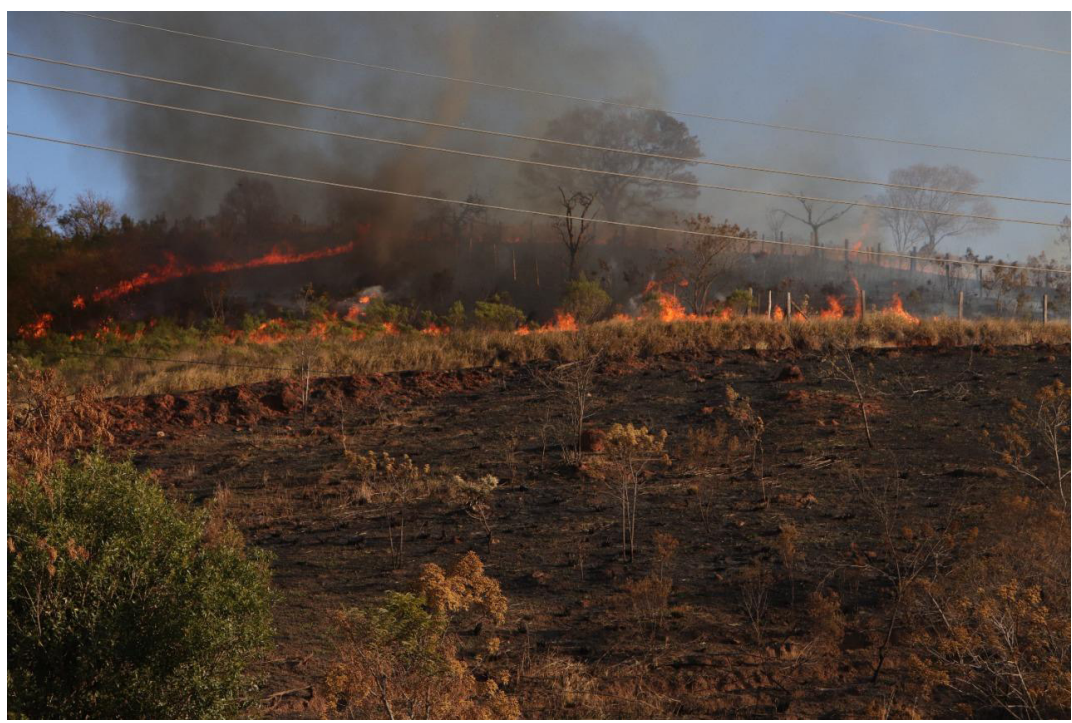

Fonte: Tirada por Bruna de Souza Fernandes e Gabriel Machado.

Em 30 de outubro de 2019, portanto, antes do mundo conhecer que estaria diante da maior pandemia de sua história — da COVID-19 —, foi proposto, como parte do projeto de Pós-Doutorado de Pedro Henrique Campello Torres (Processo FAPESP 2018/06685-9), uma sequência de eventos integrados que teria como produto final a produção de artigos sobre um tema comum: a governança do território da macrometrópole paulista (MMP). Baseado em exemplos semelhantes desenvolvidos em outras redes internacionais de pesquisa, a ideia basilar era que um pesquisador — independentemente de seu estágio de formaçáo (mestrando, doutorando e pesquisadores) — pudesse ter um espaço para desenvolver, de forma exploratória, sua pesquisa com o acompanhamento de professores especialistas no tema, de três instituiçóes de pesquisas do Estado de São Paulo (UFABC, UNIFESP e USP), com formação de diversas áreas do saber — como Biologia, Relaçóes Internacionais, Saúde Pública, Ciências Sociais, Planejamento Urbano e Ciência Ambiental. Todos vinculados ao projeto Temático "Governança Ambiental da Macrometrópole Paulista face à variabilidade climática” (FAPESP Processo 2015/03804-9) e com ampla experiência prática e de pesquisa interdisciplinar, além de interesse e aderência aos estudos sobre governança ambiental.

O desenho original da proposta previa uma Oficina presencial em 17 de agosto de 2020, o que, por razóes sanitárias, acabou não ocorrendo. No entan- 
to, com apoio dos professores-tutores e da motivação dos presentes, o processo continuou ocorrendo de forma virtual. Um passo importante foi o momento em que se colocaram perguntas norteadoras para guiar a supervisão dos textos, entre elas se o mesmo "possui contribuição original ao debate sobre Governança e a Macrometrópole Paulista?”. No dia 26 de fevereiro de 2021 os participantes deveriam apresentar publicamente o andamento de seus textos e trocar impressões tanto com seu tutor, quanto com outros professores e com outros participantes - um momento rico e balizador de expectativas, limites e caminhos.

Com os textos prontos, buscou-se e firmou-se a realização de um dossiê especial sobre a Governança da Macrometrópole Paulista, com o periódico Cadernos de Campo: Revista de Ciências Sociais, publicação vinculada ao Programa de Pós-Graduação em Ciências Sociais da Faculdade de Ciências e Letras de Araraquara (FCLAr) da Universidade Estadual Paulista "Júlio de Mesquita Filho" (UNESP). Todos os textos, portanto, passaram pelo processo formal de revisão duplo cega, e, ainda, estavam abertos a receber outros trabalhos de pessoas que não participaram das oficinas, mas que dialogavam com o tema proposto: Governanças na Macrometrópole Paulista: agendas, abordagens e possibilidades.

$\mathrm{O}$ conceito de governança tem ganhado terreno em diversas áreas do conhecimento, abordando temas, recortes e especificidades distintas (YOUNG, 2013; GONÇALVES et al., 2021). O objetivo do presente dossiê Governanças na Macrometrópole Paulista é reunir pesquisas que estejam empregando algum dos inúmeros conceitos de governança em seus trabalhos, tendo como transversalidade comum o território da Macrometrópole Paulista. O risco da banalização do uso de um conceito é sua perda explicativa e distanciamento de suas fundaçóes de origem. Nesse sentido, é imperativo o debate acerca dos usos, no campo das ciências sociais — e das ciência sociais aplicadas — sobre Governança, conceito presente em teses, projetos de pesquisas, relatórios de governos, agências, bancos, organizaçóes do terceiro setor e movimentos sociais.

A opção pelo território da Macrometrópole Paulista se dá em um momento de indefinição da região a partir da extinção da Empresa Paulista de Planejamento Metropolitano - EMPLASA, pelo Governo do Estado, até então seu principal agente condutor do planejamento e gestão (TORRES, 2021). Os temas e objetos abordados no presente dossiê são diversos e contribuem para o diálogo das ciências sociais e áreas correlatas, como o planejamento urbano e regional, a ciência ambiental, a geografia, entre outras. Os estudos sobre a Macrometrópole Paulista (MILZ; JACOBI, 2021) expóem a face diversa e heterogênea deste território - como na foto que abre este dossiê - e os contextos que remetem ao que Torres, Dos Santos e Jacobi (2021) consideram como 
a fábula, a perversidade e a possibilidade presentes nessa regiáo, no seu planejamento e na sua governança.

Dos oito artigos selecionados para compor o presente dossiê, pelo menos seis endereçam a questão ambiental de alguma forma. Tal amostra, significativa, evidencia o crescente interesse de agendas de pesquisas que entendem a necessidade de trabalhar a interface entre governança e a questão ambiental, principalmente em face aos desafios contemporâneos que vivemos. Desses seis, dois trabalham diretamente o tema da água, a saber: "Governança adaptativa da água na macrometrópole paulista: ajustes de práticas ou oportunidades para transformação?", de Ruth Ferreira Ramos, e "Gestão integrada e adaptativa da água: a governança da bacia do alto tietê em face da escassez hídrica”, de Amauri Pollachi.

Segundo Ramos, que analisa o Plano de Adaptação às Variaçóes Climáticas para a Gestão de Recursos Hidricos na Região Metropolitana de São Paulo elaborado pela $S A B E S P$, e confronta os elementos de uma governança adaptativa da água e a análise do plano, conclui que, embora haja alguns avanços nas açóes de planejamento do abastecimento público, a transição para uma governança adaptativa e resiliente da água se coloca como um importante desafio; o conjunto de informaçóes apresentadas é modesto, quando se levam em conto os principais aspectos que configuram uma governança adaptativa água. Para Pollachi, diante do evento crítico, a atuação do Comitê da Bacia do Alto Tietê quanto à participação, à integração e ao conhecimento, e a elaboração de um plano de contingência como medida antecipatória, deve ser debatidas e validadas horizontalmente pelos segmentos e pelas entidades presentes no Comitê, e também por outros protagonistas e segmentos sociais que náo estão representados.

O tema da água aparece ainda com centralidade no artigo "Pluralizando a governança pela perspectiva do nexo água-energia-alimentos: caminhos para a sustentabilidade na Macrometrópole Paulista", de Alberto Matenhauer Urbinatti e Leandro Luiz Giatti ${ }^{4}$, que trabalham a perspectiva do Nexo; assim como em "A governança multinível no planejamento energético - limitações e potencialidades para a atuação subnacional”, de Flávia Mendes de Almeida Collaço e Lira Luz Benites-Lázaro, uma vez que nossa matriz energética é predominantemente ligada à água por conta das hidrelétricas. Urbinatti e Giatti discutem de forma crítica possíveis nexos entre a governança de água, energia e alimentos no contexto da Macrometrópole Paulista, tendo como referenciais uma revisão bibliográfica nar-

${ }^{4}$ O professor Leandro Giatti tem reunido importantes contribuições na forma de projetos de pesquisas, orientações de dissertações, teses e supervisões de pós-doutorado, além de um considerável número de artigos científicos sobre o tema. 
rativa e uma análise de conteúdo da Carteira de Projetos do Plano de Ação para a Macrometrópole Paulista 2013-2040 (PAM), sinalizando que este náo considera de maneira mais aprofundada experiências humanas de atores mais vulneráveis em relação ao acesso aos recursos no contexto macrometropolitano. Collaço e Benites-Lazaro analisam a governança multinível do arcabouço de políticas de energia no Brasil, salientando suas limitaçóes e possibilidades para alavancar a atuação em planejamento energético $(\mathrm{PE})$ na região da Macrometrópole Paulista, e apontam para a falta de integração entre as políticas apesar de existirem vários elementos com potencial de alavancar a atuação multinível em PE, principalmente por meio das leis e políticas de mudança climática.

Mudanças climáticas, tema transversal aos estudos supracitados, é destaque em "Governança Ambiental na Gestão Pública para o Enfrentamento às Mudanças Climáticas: Desafios de Pequenos Municípios a partir de um estudo de caso", de Gabriel Pires de Araújo. Aqui um destaque importante do estudo e da contribuição do presente dossiê. A composição de artigos permite ao leitor a montagem singular de um verdadeiro caleidoscópio, em que se pesam diferentes abordagens multiescalares, sem cair, é bem verdade, como ensina Sandra Lencioni na

[...] armadilha da matrioska, das bonecas russas, em que uma série de bonecas de diferentes tamanhos, tradicionalmente feitas de madeira, se encaixam umas às outras, sendo cada uma independente das demais. Ao contrário disso, cada escala examinada náo é apenas e tão somente vista em si mesma, mas é interpretada, também, na relação com as outras escalas (LENCIONI, 2022, p. 2).

Ao trazer a discussão sobre mudanças climáticas e pequenos municípios, o artigo traz elementos concretos para um verdadeiro debate sobre conexóes entre o local e o global, suas interdependências e capacidades.

Fechando o bloco ambiental do dossiê temos o artigo "Governança da Coleta Seletiva de Resíduos Sólidos Urbanos: Mapeamento dos atores presentes no Município de São Paulo", de Erica Aparhyan Stella, Isabela Ribeiro Borges de Carvalho, Kelly Danielly da Silva Alcantara Fratta, Lilian Ferreira dos Santos Lacerda, Luciana Aparecida Iotti Ziglio e Sylmara Lopes Francelino GonçalvesDias. Neste artigo, as autoras caracterizam os atores e as relaçóes presentes na governança da coleta seletiva de resíduos sólidos urbanos no município de São Paulo, utilizando de revisão de literatura de fontes secundárias, pesquisa documental e software para a construção do mapa de atores como estratégia meto- 
dológica, mostrando que o elemento relacional do padrão de governança da coleta seletiva pode ser caracterizado como uma ampla rede de atores diversos, vagamente centrada no tecido relacional do Estado.

Compondo a discussão, outros dois artigos abordam a temática do planejamento urbano e regional e da governança: "Apontamentos sobre governança e planejamento na Região Metropolitana de Sorocaba (São Paulo - Brasil)”, de Igor Matheus Santana-Chaves, Ana Lia Leonel, Lidiane Alonso Paixão dos Anjos, Sandra Momm e Márcio José Catelan, e "Limites e potencialidades do planejamento e governança regional: A Região Metropolitana do Vale do Paraíba e Litoral Norte na Macrometrópole Paulista” de Rosa Scaquetti, Pedro Ribeiro Moreira e Lidiane Maciel.

No que diz respeito ao artigo sobre a Região Metropolitana de Sorocaba, os autores contribuem com a discussão sobre transformaçóes das estruturas e práticas de governança e planejamento em áreas metropolitanas por meio de um diálogo dedutivo-indutivo. E, a partir da análise e da revisão da literatura, discutem possíveis estratégias institucionais com vistas a promover práticas políticas mais interativas e democráticas entre os diferentes níveis de governança numa perspectiva multiescalar, seus efeitos nos sistemas de governança atualmente institucionalizados e sua efetividade para integração do planejamento nas metrópoles. No caso do artigo em torno da Região Metropolitana do Vale do Paraíba e Litoral Norte (RMVPLN), se parte da constatação do descompasso entre as iniciativas de governança e as açóes efetivamente implementadas no contexto do estado de Sáo Paulo no período da criação do Estatuto da Metrópole, ocorrido em 2015, e se analisa o processo de criação e institucionalização dessa Região Metropolitana, tendo como hipótese a centralidade do planejamento em escala regional, tomando como base uma pesquisa quanti-qualitativa descritiva que se utiliza de dados publicados por instituiçóes de pesquisa, mídias sociais e entrevistas.

Portanto, os artigos reunidos oferecem ao leitor um conjunto interdisciplinar de olhares plurais necessários à comprensão da realidade sombria que ronda os ataques às instituiçóes públicas, seja no setor de planejamento, ou no campo da educação, da ciência e do serviço público como um todo. A face neoliberal presente em agendas governamentais que buscam liquidar não apenas o patrimônio público existente, mas também neutralizar a crítica, cooptando coraçóes e mentes, precisa ser denunciada e exposta de maneira clara. Esse movimento, contraponto à agenda capitalista hegemônica — colonialista e privatista - é o norte de esperança e luta para transiçóes justas, sem maquiagens verdes, com a superação de desigualdades e a radicalização da democracia. 


\section{REFERÊNCIAS}

GONÇALVES, L. R.; FIDELMAN, P.; TURRA, A.; YOUNG, O. The Dynamics of Multiscale Institutional Complexes: the Case of the São Paulo Macrometropolitan Region. Environmental Management, Jeffersonville, v. 67, n. 1, p. 109-118, 2021.

LENCIONI, S. Prefácio. In: TORRES, P. H. C. et al. Ordenamento e Governança da Macrometrópole Paulista: desafios de pesquisa interdisciplinar sobre complexidade territorial. Jundiaí: Paco Editora, 2022. p.2-3.

MILZ, B.; JACOBI, P. R. Levantamento de estudos sobre a macrometrópole paulista entre os anos de 2010 e 2020. In: JACOBI, P. R.; GIATTI, L. L. (org.). Inovaçáo para governança da Macrometrópole Paulista face à emergência climática. Curitiba: Ed. CRV, 2021. p. 179-190.

TORRES, P. H. C. Macrometrópole Paulista: Terra ignota? In: JACOBI, P. R.; GIATTI, L. L. (org.). Inovaçáo para governança da Macrometrópole Paulista face à emergência climática. Curitiba: Ed. CRV, 2021. p. 157-174.

TORRES, P. H. C.; DOS SANTOS, K., L.; JACOBI, P. R. A Macrometrópole Paulista em três tempos: fábula, perversidade e possibilidade. In: TORRES, P. H. C. et al. Ordenamento e Governança da Macrometrópole Paulista: desafios de pesquisa interdisciplinar sobre complexidade territorial. Jundiaí: Paco Editora, 2021. p.21-32.

YOUNG, O. R. On environmental governance: Sustainability, Efficiency, and Equity. Boulder: London: Paradigm Publishers, 2013. 